\title{
Molecular characteristics and serodiagnostic potential of chitinase-like protein from Sarcoptes scabiei
}

\author{
Ran He ${ }^{1, *}$, Nengxing Shen ${ }^{1, *}$, Haojie Zhang ${ }^{1, *}$, Yongjun Ren ${ }^{2}$, Manli $\mathrm{He}^{1}$, Jing $\mathrm{Xu}^{1}$, \\ Cheng Guo ${ }^{1}$, Yue Xie ${ }^{1}$, Xiaobin Gu${ }^{1}$, Weimin Lai ${ }^{1}$, Xuerong Peng ${ }^{3}$ and Guangyou \\ Yang $^{1}$ \\ ${ }^{1}$ Department of Parasitology, College of Veterinary Medicine, Sichuan Agricultural University, Wenjiang, China \\ ${ }^{2}$ Sichuan Animal Sciences Academy, Sichuan Chengdu, China \\ ${ }^{3}$ Department of Chemistry, College of Life and Basic Science, Sichuan Agricultural University, Wenjiang, China \\ *These authors contributed equally to this work
}

Correspondence to: Guangyou Yang, email: guangyou1963@aliyun.com

Keywords: chitinase-like protein, Sarcoptes scabiei, enzyme-linked immunosorbent assay, immunolocalization, intradermal skin test

Received: May 23, 2017 Accepted: September 03, $2017 \quad$ Published: September 19, 2017

Copyright: He et al. This is an open-access article distributed under the terms of the Creative Commons Attribution License 3.0 (CC BY 3.0), which permits unrestricted use, distribution, and reproduction in any medium, provided the original author and source are credited.

\section{ABSTRACT}

Scabies, caused by the mite Sarcoptes scabiei, is an allergic skin disease that affects millions of people and other mammals worldwide. This highly contagious parasitic disease is among the top $\mathbf{5 0}$ epidemic disease and is regarded as a neglected tropical disease. Diagnosis of scabies is difficult in the early stage, and the pathogenesis of scabies is not currently clear. Here, we expressed, identified and located the chitinase-like protein of S. scabiei (SsCLP), and evaluated its potential as an early-stage diagnostic antigen for rabbit scabies. Indirect ELISA using recombinant SsCLP (rSsCLP) exhibited diagnostic sensitivity of $94.4 \%(17 / 18)$ and specificity of $86.7 \%(26 / 30)$. Early diagnostic test after artificial infection of rabbits with $S$. scabiei for 1 week showed a positive detection rate of $96.7 \%(29 / 30)$. Immunolocalization assays showed that fluorescence signals were localized on the surface of mites and, in infected rabbits, were observed in keratinized skin and embedded mites. Intradermal skin tests of rabbits by injecting rSsCLP showed a wheal, flare and erythema reaction. These results suggest that $S$. scabiei chitinase-like protein is conducive to host invasion, participates in inducing the allergic response of the host, and is an effective antigen for the diagnosis of S. scabiei.

\section{INTRODUCTION}

Scabies, caused by the mite Sarcoptes scabiei, is a parasitic and contagious skin disease that affects humans and other mammals worldwide [1]. Scabies is listed as a neglected tropical disease and represents a significant public health threat, especially in economically disadvantaged populations [2, 3]. It also infects more than 100 species of livestock and wild animals, which results in a significant economic burden [4]. S. scabiei mites parasitize the host throughout their life-cycle (adults, nymphs and larvae), and mites can sense the temperature and smell of a host [5]. The pathogenicity of the larvae is the strongest, and direct contact with the skin can cause infection of a healthy host in less than $20 \mathrm{~min}$. The mites burrow into the skin and obtain nutrients from serum and epidermal cells, causing severe itching, scabs and skin thickening, which potentially result in appetite loss, and secondary bacterial infections [6-9].

Chitinase-like protein (CLP) belongs to the glycoside hydrolase family 18 [10], CLPs participate in a variety of biological functions [11-15], including inflammatory reactions and infections. CLPs cleave the chitin of arthropods, fungi and parasites. Some CLPs have no enzymatic activity because of loss of function mutations but they can contribute to airway pathology [16]. It has been reported that CLPs have a critical role in both innate and adaptive type 2 immune responses [17-19], which indicates that they may have the potential for specific antibody detection. Currently, the diagnosis of scabies is mainly based on clinical characteristics, which 
makes misdiagnosis (e.g., as atopic dermatitis, eczema, hairless tinea or insect bites) a distinct possibility [20]. Thus, searching for an antigenic component of scabies with high diagnostic sensitivity and specificity is a crucial task. Meanwhile, in our transcriptome-microRNA analysis of Sarcoptes scabiei and host immune response [21], differential expression analysis showed that CLP of $S$. scabiei was upregulated after host infection, indicating that $S$. scabiei secretes more CLP after the invasion of host. Moreover, the Kyoto Encyclopedia of Genes and Genomes pathway analysis showed that CLP of $S$. scabiei participates in chitosan biosynthesis, chitosan participate in the improvement of immune response [22]. Therefore, exploration of the distribution of CLPs in mites and infected skin may contribute to understanding mite pathogenesis and the immune responses of hosts.

This study aimed to analyze the molecular characteristics of the chitinase-like protein from S. scabiei, and explore the role of the CLP in mite pathogenesis. We also assess the serodiagnostic potential of S. scabiei CLP.

\section{RESULTS}

\section{Molecular characterization of $S$. scabiei CLP (SsCLP)}

The SsCLP cDNA (GeneBank accession number: KY904739) contained a 1275-bp ORF that encoded a putative protein of 424 amino acids. The predicted molecular mass of the protein was $47.6 \mathrm{kDa}$, and the isoelectric point was 9.16. No signal peptides were predicted. Multiple sequence alignment revealed that the SsCLP amino acid sequence shares $51-67 \%$ overall identity with proteins from Limulus polyphemus, Parasteatoda tepidariorum, Tetranychus cinnabarinus, Monochamus alternatus, Amblyomma sculptum, Stegodyphus mimosarum, and Megachile rotundata. The SsCLP amino acid sequence contains a chitin-binding type- 2 domain, characterized by a six-cysteine motif and several aromatic residues [23, 24] (Figure 1).

\section{Expression and identification of rSsCLP}

The cDNA encoding SsCLP was successfully subcloned into the pET32a $(+)$ expression vector and expressed in Escherichia coli BL21 (DE3). The molecular weight (Mw) of recombinant SsCLP (rSsCLP) of approximately $63 \mathrm{kDa}$ (including the His tag) (Figure 2) was similar to the predicted Mw. rSsCLP was purified using a Ni-chelating column and examined by SDS-PAGE (Figure 2). Immunoblotting using anti-rSsCLP rabbit serum and S. scabiei-positive rabbit serum showed a single band at approximately $63 \mathrm{kDa}$, indicating good antigenicity of rSsCLP. No signal was present when rSsCLP was incubated with naïve (healthy) rabbit serum (Figure 2).

\section{Establishment of indirect ELISA (iELISA)}

Using a checkerboard titration protocol, the optimal concentration of the rSsCLP antigen and optimal working dilution of the serum for ELISA were found to be $0.5 \mu \mathrm{g} /$ well and 1:100 respectively. In these optimized conditions, sera from 12 negative rabbits were analyzed. The optical density was read at $450 \mathrm{~nm}\left(\mathrm{OD}_{450 \mathrm{~nm}}\right)$ using microplate reader (Termo Scientifc, Pittsburgh, PA, USA). The mean $\mathrm{OD}_{450 \mathrm{~nm}}$ value was 0.242 and the standard deviation was 0.0677 ; thus the cut-off value was calculated as 0.445 (mean $+3 \mathrm{SD})$. The interassay coefficients of variation $(\mathrm{CVs})$ ranged from $1.24 \%$ to $5.17 \%$ (mean $=3.205 \%)$, while the intra-assay CVs ranged from $2.51 \%$ to $9.18 \%$ $($ mean $=5.845 \%)$. The coefficients were $<10 \%$, which means this assay was repeatable and reproducible.

\section{Sensitivity and specificity of the iELISA}

Serum from 48 rabbits (18 S. scabiei-positive, six Taenia pisiformis-positive, 12 Psoroptes cuniculi-positive, and 12 Eimeria spp.-positive) were tested in the iELISA. Serum from 17 rabbits infected with S. scabiei was detected as positive, corresponding to an assay sensitivity of $94.4 \%$ (17/18) (Figure 3A). There was no cross-reactivity between the rSsCLP antigen and serum from rabbits infected with T. pisiformis or Eimeria spp., but cross-reactivity was observed with four samples of serum from rabbits infected with P. cuniculi, corresponding to a specificity of $86.7 \%$ (26/30) (Figure 3A). Moreover, statistical differences were observed in the ELISA values between the S. scabieipositive sera and other positive or negative sera $(P<0.05$; data not shown). No differences were noted between the other positive sera and negative sera.

\section{Early diagnosis test of iELISA}

After artificial infection of 30 rabbits with S. scabiei, the $\mathrm{OD}_{450 \mathrm{~nm}}$ of serum samples from 29 rabbits was higher than cut-off value after 1 week (Figure 3B) $(P<0.05)$. The serum samples collected before infection showed lower $\mathrm{OD}_{450 \mathrm{~nm}}$ values than the cut-off.

\section{Hematoxylin and eosin $(\mathrm{H} \& \mathrm{E})$ and Immunolocalization}

H\&E staining results showed that scabies invaded the epidermis of the host (rabbit) skin (Figure 4). SsCLP was localized in starved mites and infected skin by an immunofluorescence method. In starved mites, the fluorescence signals were localized on the surface of the mites (Figure 5). In infected rabbits, fluorescence signals were observed in keratinized skin and embedded mites (Figure 6). No fluorescence signals were detected in the negative controls for starved mites (Figure 5) and infected skin. 


\section{Intradermal skin test}

No reaction was induced by $0.9 \%$ physiological saline, PBS or empty expression vector. Histamine, the positive control, produce a wheal reaction. Rabbits injected with rSsCLP showed a wheal, flare and erythema reaction (Figure 7).

\section{DISCUSSION}

Chitinase-like proteins are a mediator family associated with allergy, infection and $\mathrm{T}$ cell-mediated inflammation in mammals [25-27]. CLPs were found to limit nematode survival but at the expense of increased lung injury [28]. It has been reported that CLPs are often dysregulated in patients with various disorders and they may influence the Th1 and Th2 balance, affecting inflammatory response and tissue remodeling thus serving as useful diagnostic markers $[29,30]$. CLPs have been studied extensively in a variety of organisms, including mammals [19, 31], insects [15] and plants [32, 33], but CLP has not been described in S. scabiei. Here we cloned, expressed and established an iELISA method based on rSsCLP to diagnose scabies, and investigated the involvement of SsCLP in the pathogenesis of scabies.

Scabies causes health problems and economic burdens worldwide, and clinical diagnoses depending on clinical signs of $S$. scabiei infection mimic symptoms of other skin diseases [34] (e.g., as atopic dermatitis, eczema, hairless tinea or insect bites). Microscopy diagnoses depending on observation of mites, egg, fecal pellets, eggshell fragments and/or mite fecal pellets from skin scrapings [35], but it is difficult to identify accurately and scraping lesions. Noninvasive diagnoses, such as videodermatoscopy, dermoscopy, reflectance confocal microscopy, and optical coherence tomography, is rapid and no physical risk. But optical coherence tomography and reflectance confocal microscopy are available only in some selected centers. Dermoscopy has been demonstrated more accurate with skin scraping and videodermatoscopy is performed with digital systems (computer and video camera) [36-38]. Mange-detector dogs seem more suitable for wildlife surveillance and control, meanwhile the sensitivity and specificity of this tool has not been identified [39]. Although diagnoses depending on universal conventional and real-time PCR have high specificity and technical sensibility, these diagnosis tools need to collect mites first, and may not suitable for early diagnosis of S. scabiei [36, 40-43]. Thus establishing a fast, inexpensive and accurate diagnostic method for $S$. scabiei in live animals is necessary. Here we established an iELISA based on recombinant SsCLP, and it was optimized to diagnose infected rabbits. And rabbit serum positive for P. cuniculi, T. pisiformis, and Eimeria spp. were chosen to perform the cross-reaction, because they are the most common parasites of rabbit.

Previous research using recombinant proteins including Sar s 14.3, thioredoxin peroxidase, Pso o 2 , Ss $\lambda 20 \Delta 3$ and cofilin as antigens in iELISA showed potential value for diagnosis of S. scabiei [44-47]. Compared with iELISA using other recombinant proteins as diagnostic antigens, rSsCLP shows considerable sensitivity (94.4\%) and specificity (86.7\%). In addition, the early diagnosis of 30 rabbit serum samples after artificial infection for only 1 week showed a high positive detection rate of $96.7 \%(29 / 30)$. Interestingly, the $\mathrm{OD}_{450 \mathrm{~nm}}$ values of sera after artificial infection for 2 weeks were not significantly different from those after 1 week. These data indicate that SsCLP participates in the early stage of S. scabiei-host immune interaction and induces an early immune response of the host, after which secretion of the host antibody showed no significant change.

H\&E staining results showed that scabies invaded the epidermis of the host rabbit skin (Figure 4) S. scabiei burrows into the skin and obtains nutrients from the host serum and epidermal cells. Mites dig tunnels and spawn within the skin; larvae can leave the tunnels and drill into skin from the hair follicles [6-8]. In starved mites, CLP fluorescence signals were localized to the surface of the mites (Figure 5A, 5B), and in infected rabbits, fluorescence signals were observed

\begin{abstract}
MQTKHPDMSTVWDPYYLAPYS FWGRQWVGYDNVES IAIKSQYAKAMGLGGGMIWS IETDDFGGYCN QGRYPLLRAIRKVFDDPKKAFMPKPDQQSKQPHETTKPPSTPSFPPQQTTKFPTQPSKPSSKPSYP PKKTTKFPPQTTKPSIPPQQTTKFPPQTSKPSSKSPQTTITTKILTTKPWTTTTVTQGTSTSIVTT KQPSSPSSTTRKPVTMPDSESTTNRCKRPRPTTKRTTPSTTTTQSSTEFTTLRPPSESSSTSESSK KWWSESTPWWPTKPSKHASPGITTWWAATFPPSRKNPNAIEENPSSKDSDILIMKESSQSFTCTGS GLFRNPESCTKFIRCVETDIEDQFQLFFYECPDKTVFNSKTQLCDWVENVPDCLDSVPKYYFRGIN FQNKGVVAIVNKGIGVFNDDEDGEDETQ
\end{abstract}

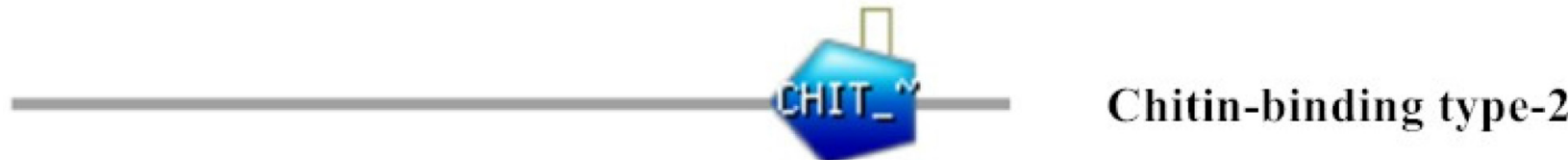

Figure 1: Sequence and functional domain analysis of Sarcoptes scabiei chitinase-like protein (SsCLP). 
in keratinized skin and embedded mites (Figure 6). Thus, SsCLP is distributed on the surface of the mites and dispersed in the infected skin of the host. It has been reported that secretory proteins play a key role in infection of parasites, as well as in immunoregulation of the host and immune system evasion $[48,49]$. Parasites produce secretory proteins and release them directly into host fluids and tissues.

Secretory proteins of some parasites (such as mites) are important allergens that induce an inflammatory response of the host [50-52]. Sixty-one allergen unigenes have been predicted in the transcriptome of $S$. scabiei canis [53], and groups of allergen genes had been identified in the draft genome of the scabies mite [2]. When we compared our transcriptome data with dust mite allergen, we found homologous allergen unigenes. Among genome and transcriptome of $S$. scabiei canis and transcriptome of S. scabiei cuniculi, CLP share more homology with group 15 allergen of the house dust mite (HDM). The sequence we cloned and expressed contained a chitin-binding type-2 domain. Group 15, 18 and 23 dust mite allergens contain sequences similar to chitin-binding domains, and have been identified as major HDM allergens [54]. These proteins containing chitin-binding domain may provide important evidence for nutrient procurement, digestion and defecation of S. scabiei [55]. In intradermal skin tests (Figure 7), rSsCLP injection into rabbit induced a wheal, flare and erythema reaction. Scabies is an allergic skin disease caused by allergens, most mite allergens are proteases and they can promote inflammation and allergic reactions, including rhinitis, asthma and dermatitis
[56-58]. It has been reported that Der $\mathrm{p} 1$ and Der $\mathrm{p} 2$ (allergens from the house dust mite Dermatophagoides pteronyssinus) may increase allergic immune responses of the host by respectively cleaving $\operatorname{IgE}$ receptors and boosting the innate immune response $[59,60]$. Cockroach allergens induce immunologic responses by activating innate immune cells (such as dendritic cells) by binding to either Toll-like receptors or C-type lectin receptors [61]. These findings suggest that S. scabiei allergens may play a crucial role in the pathogenesis of scabies. Wheal, flare and erythema reactions are common symptoms of allergic skin disease, indicating that rSsCLP can induce specific, immediate hypersensitivity responses. Moreover, H\&E staining and immunolocalization provided evidence of mite invasion and protein distribution in the skin, and the early diagnosis iELISA indicated that SsCLP participated in the early stage of the $S$. scabiei-host immune interaction and induced an immune response of the host. These results correspond to our transcriptome-microRNA analysis results, and suggest that SsCLP is conducive to host invasion, participates in inducing the allergic response of the host, and is an effective antigen for the diagnosis of S. scabiei.

\section{MATERIALS AND METHODS}

\section{Ethics statement}

Animals were handled strictly according to the animal protection law of the People's Republic of China

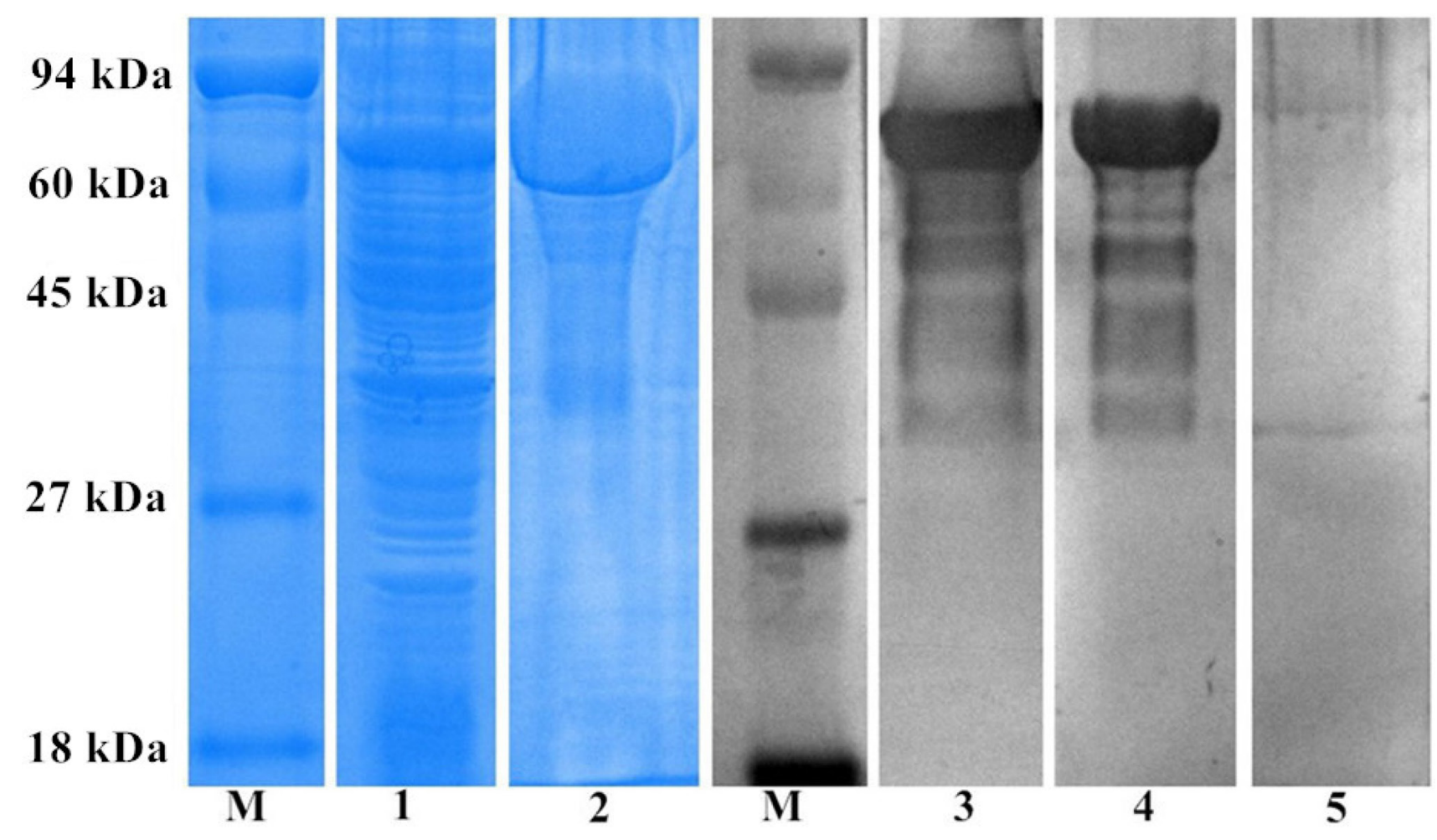

Figure 2: SDS-PAGE and western blotting analysis of SsCLP. M, protein molecular-weight markers; lane 1, expressed rSsCLP; lane 2, purified rSsCLP; lane 3, purified rSsCLP probed with anti-rSsCLP rabbit serum; lane 4, purified rSsCLP probed with S.scbiei positive rabbit serum; lane5, purified rSsCLP probed with native rabbit serum. 
(released on 09/18/2009) and the National Standards for Laboratory Animals in China (executed on 05/1/2002). This study was reviewed and approved by the Animal Ethics Committee of Sichuan Agricultural University (China) (Approval No. 2013-028). All the methods were carried out in accordance with all relevant guidelines and regulations.

\section{Mites and animals}

Mites (adults, nymphs and larvae) collected from rabbits were provided by the Department of Parasitology, College of Veterinary Medicine, Sichuan Agricultural University. The mites were stored in liquid nitrogen prior to RNA extraction and were unfed prior
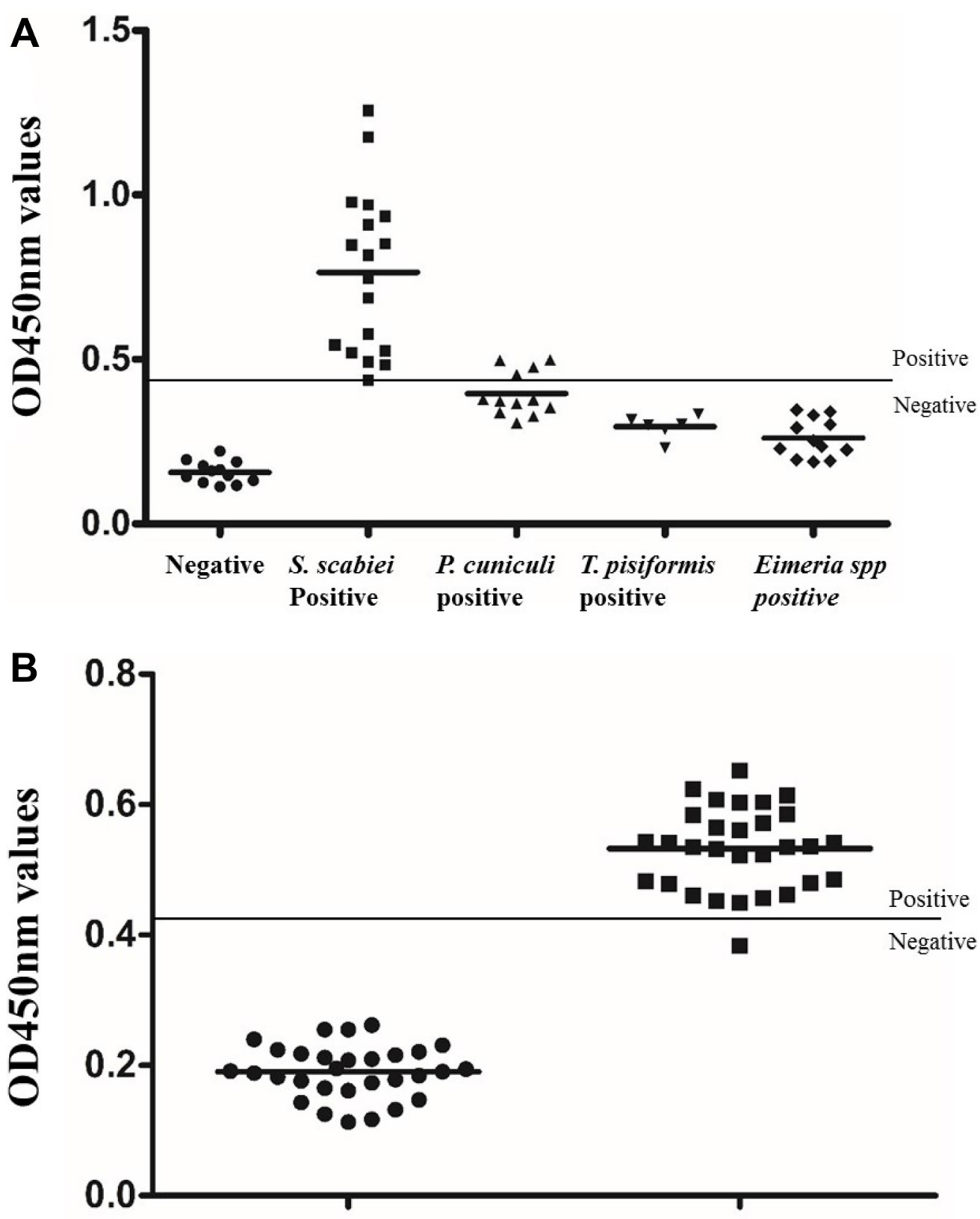

\section{Before artificial infestation}

\section{After artificial infestation}

Figure 3: Sensitivity, specificity and early diagnosis test of indirect ELISA ( $\boldsymbol{P}<\mathbf{0 . 0 5})$. (A) "Negative": OD ${ }_{450 \mathrm{~nm}}$ values of rabbit naïve serum samples $(n=12)$; "S.scabiei positive": $\mathrm{OD}_{450 \mathrm{~nm}}$ values of rabbit serum positive for S.scabiei ; "P.cuniculi positive": $\mathrm{OD}_{450 \mathrm{~nm}}$ values of rabbit serum positive for Psoroptes cuniculi $(n=12)$; "T. pisiformis positive": $\mathrm{OD}_{450 \mathrm{~nm}}$ values of rabbit serum positive for Taenia pisiformis $(n=6)$; "E.spp positive": $\mathrm{OD}_{450 \mathrm{~nm}}$ values of rabbit serum positive for Eimeria $\mathrm{spp}(n=12)$; $(\mathbf{B})$ "Before artificial infection": $\mathrm{OD}_{450 \mathrm{~nm}}$ values of rabbit serum samples that collected before artificial infection $(n=30)$. "After artificial infection": $\mathrm{OD}_{450 \mathrm{~nm}}$ values of rabbit serum samples that collected after artificial infection for 1 week $(n=30)$. 
to experiments. New Zealand White rabbits (8-weeksold) were obtained from the Laboratory Animal Center of Sichuan Agricultural University (Ya'an, China). All rabbits were housed in a barrier environment in sterile cages and provided with pelleted food and sterilized water ad libitum. Rabbits were acclimated to these conditions for 1 week before experiments.

\section{Bioinformatic analysis of SsCLP}

The SsCLP sequence was obtained from our transcriptome data of S.scabiei (NCBI Bio Project ID: PRJNA320671). Biochemical parameters such as molecular weight and isoelectric point were predicted using the ExPASy Proteomics Server (http://web. Expasy.org/protparam/). The open reading frame (ORF) was determined using ORF Finder (http://www.ncbi. nlm.nih.gov/orffinder/). Signal peptides were predicted using the SignalP 4.1 Server (http://www.cbs.dtu.dk/ services/SignalP/). Multiple sequence alignment was performed using DNAMAN 3.0 (Lynnon Biosoft, Canada). The amino acid sequences were translated using BioEdit (http://www.mbio.ncsu.edu/BioEdit/bioedit. html\#downloads) and functional domains were scanned using PROSITE (http://prosite.expasy.org/scanprosite/).

\section{Expression and identification of rSsCLP}

Total RNA was isolated from mites by using an RNA Extraction Kit (Cowin Biotech, China), according to the manufacturer's instructions. cDNA was transcribed using the RevertAi ${ }^{\mathrm{TM}}$ First Strand cDNA Synthesis Kit (Thermo, USA), according to the manufacturer's instructions, and stored at $-80^{\circ} \mathrm{C}$. The region that encodes rSsCLP was amplified for expression by using primers (5'-GGGGTACCTTGTGAAATGCAAACTAA-3'; 5'-CG AGCTCTTCACTGAGTTTCATCCT-3').
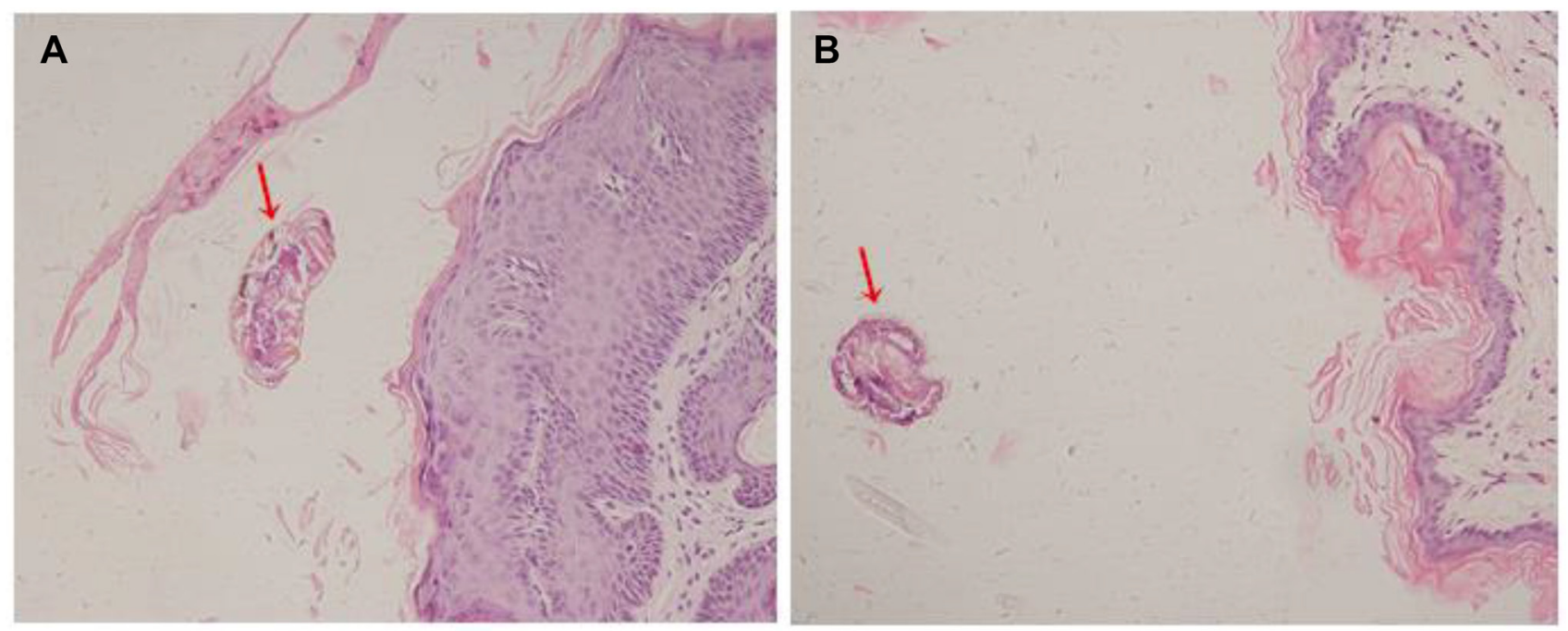

Figure 4: Hematoxylin and eosin (H\&E) staining of S.scabiei infected rabbit skin. (A and B). S. scabiei invaded the epidermis of skin. 
was injected subcutaneously into New Zealand White rabbits at first immunization. Second and third booster injections were given at 2-week intervals and consisted of $100 \mu \mathrm{g}$ protein with equal volumes of Saponin adjuvant. The last immunization was an injection of $200 \mu \mathrm{g}$ rSsCLP. The rabbit antisera were collected 1 week after the final immunization. The antibody titer was determined by ELISA. Immunoglobulin $\mathrm{G}$ (IgG) was isolated from the antisera using a Protein G-Sepharose column (Bio-Rad) according the manufacturer's instructions.

After purification, rSsCLP was mixed with electrophoresis sample buffer and boiled for $10 \mathrm{~min}$. Then, the samples were separated by $12 \%$ SDS-PAGE and transferred onto nitrocellulose membranes for $35 \mathrm{~min}$ in an electrophoretic transfer cell (Bio-Rad). The membrane was blocked with $5 \%$ skim milk for $2 \mathrm{~h}$, followed by incubation overnight with $\operatorname{IgG}$ or serum positive for $S$. scabiei $(1: 100$ dilution) at $4^{\circ} \mathrm{C}$. Then, the membrane was washed three times with Tris-buffered-saline-Tween20 (TBST) and incubated for $2 \mathrm{~h}$ with horseradish peroxidase (HRP)conjugated goat anti-rabbit IgG (1:3000; Boster, China). The protein signals were visualized with the Enhanced HRP-DAB Chromogenic Substrate Kit (Tiangen, China), according to the manufacturer's instructions. The serum of naïve (healthy) rabbits was used as the negative control.

\section{iELISA development and serum detection}

iELISA was used to evaluate the serodiagnostic potential of rSsCLP. It was performed in polystyrene 96-well microtiter plates (Invitrogen) coated overnight at $4^{\circ} \mathrm{C}$ with $100 \mu \mathrm{L}$ reaction mixtures of eight different concentrations of rSsCLP in 0.1 M carbonate buffer ( $\mathrm{pH}$ 9.6). After washing three times with $0.1 \mathrm{M}$ phosphate-buffered saline containing
Tween 20 (PBST), each well was blocked with $100 \mu \mathrm{L}$ of skim milk in PBS (5\%) for 90 min at $37^{\circ} \mathrm{C}$. Serial twofold dilutions (in PBS) of positive and negative serum samples were used in the following steps. After washing three times with PBST, goat anti-rabbit IgG-HRP conjugate $(100 \mu \mathrm{L}, 1$ : 3000; Earth Ox, USA) was added to each well and incubated for $60 \mathrm{~min}$ at $37^{\circ} \mathrm{C}$. Antibody binding was detected with $100 \mu \mathrm{L}$ of 3,3',5,5'-tetramethylbenzidine (TMB; Tiangen, China), and the optical density was measured at $450 \mathrm{~nm}$. After the optimal dilutions of rSsCLP antigen and rabbit serum were determined, the cut-off value was defined as the mean $\mathrm{OD}_{450 \mathrm{~nm}}$ absorbance value plus three times the standard deviation from the 12 negative rabbit serum samples.

Intraplate repeatability was evaluated by the coefficient of variation ( $\mathrm{CV} \%$ ) of every serum sample. Three separate assays were used to evaluate the interplate repeatability.

\section{Sensitivity and specificity of indirect ELISA analysis}

To evaluate the sensitivity of the rSsCLP iELISA, 18 S. scabiei-positive rabbit sera were tested. The specificity was evaluated from the cross-reaction with antibodies derived from rabbit serum positive for $T$. pisiformis $(n=6)$, P. cuniculi $(n=12)$, and Eimeria spp. $(n=12)$. The sensitivity of the assay was calculated as: sensitivity $(\%)=$ ELISA positive/true positive $\times 100$. The specificity of the assay was calculated as: specificity $(\%)=$ ELISA negative/true negative $\times 100$.

\section{Early diagnosis test by iELISA}

To assess the early diagnosis potential of rSsCLP, serum samples from 30 rabbits were tested after artificial
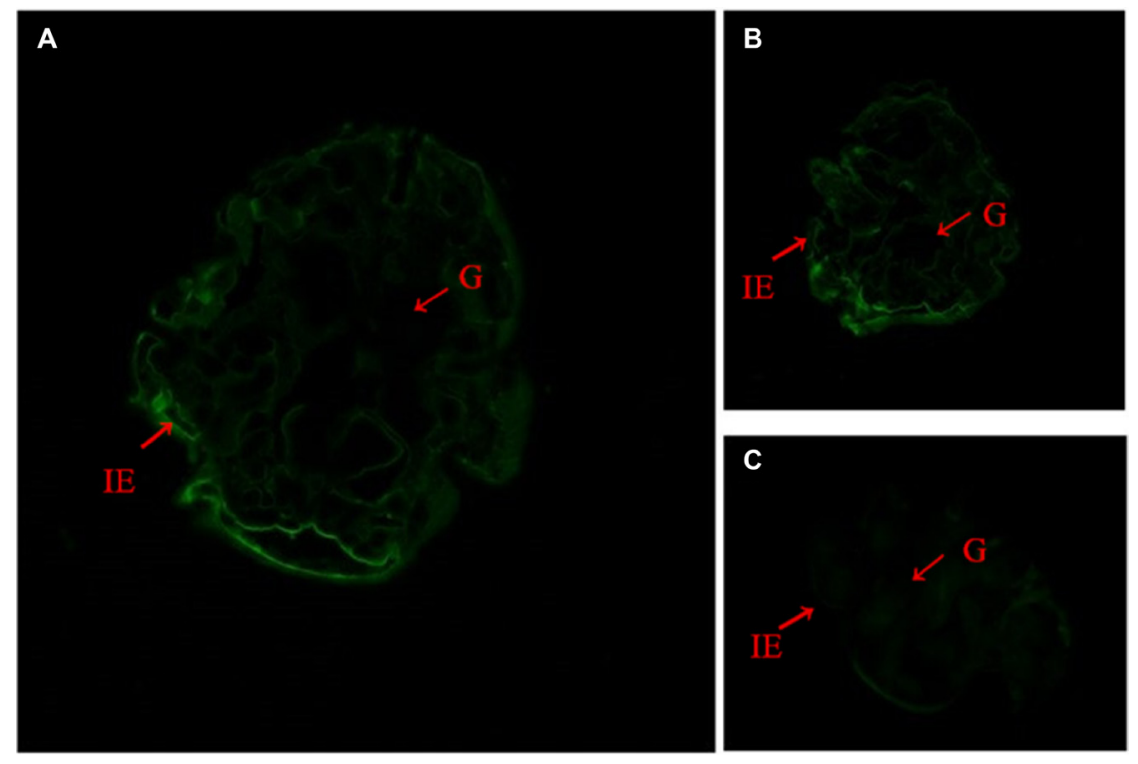

Figure 5: Immunofluorescent localization of SsCLP in starved mites. (A and B), SsCLP was distributed on the surface of mites; (C), negative control. Annotation: IE, epidermal integument; G, gut. 
infection with S. scabiei for 1 and 2 weeks. The diagnostic rate was calculated based on the cut-off value. Each serum sample was tested three times.

\section{H\&E staining and fluorescence immunohistochemistry assay}

Starved mites (mites collected and starved for $12 \mathrm{~h}$ before being stored in liquid nitrogen) and skin samples were collected from the feet of S. scabiei-infected rabbits. Samples were fixed in 1\% molten agarose and set in paraffin wax after solidification of the molten agarose. The infected skin and starved mite samples were fixed in $4 \%$ paraformaldehyde in PBS ( $\mathrm{pH} 7.4$ ) for $24 \mathrm{~h}$. A rotary microtome was then used to cut the embedded samples into 5 - $\mu \mathrm{m}$-thick sections.

To make the results of fluorescent immunohistochemistry clearer, H\&E staining was performed as a control. Then the sections were rehydrated by immersing the slides successively in xylene (twice, for $7 \mathrm{~min}$ each), 100\% ethanol (twice, for $3 \mathrm{~min}$ each), 95\% ethanol for $3 \mathrm{~min}, 85 \%$ ethanol for $3 \mathrm{~min}, 75 \%$ ethanol for $3 \mathrm{~min}$, and deionized $\mathrm{sH}_{2} \mathrm{O}$ for 8 min followed by blocking with $3 \% \mathrm{H}_{2} \mathrm{O}_{2}$. The sections were then washed and incubated overnight with purified $\operatorname{IgG}$ fractions (diluted 1:100 in PBS) at $4^{\circ} \mathrm{C}$. Subsequently, the sections were washed and incubated with fluorescein isothiocyanate-conjugated goat anti-rabbit IgG (H + L; AMRESCO, Texas, USA) diluted
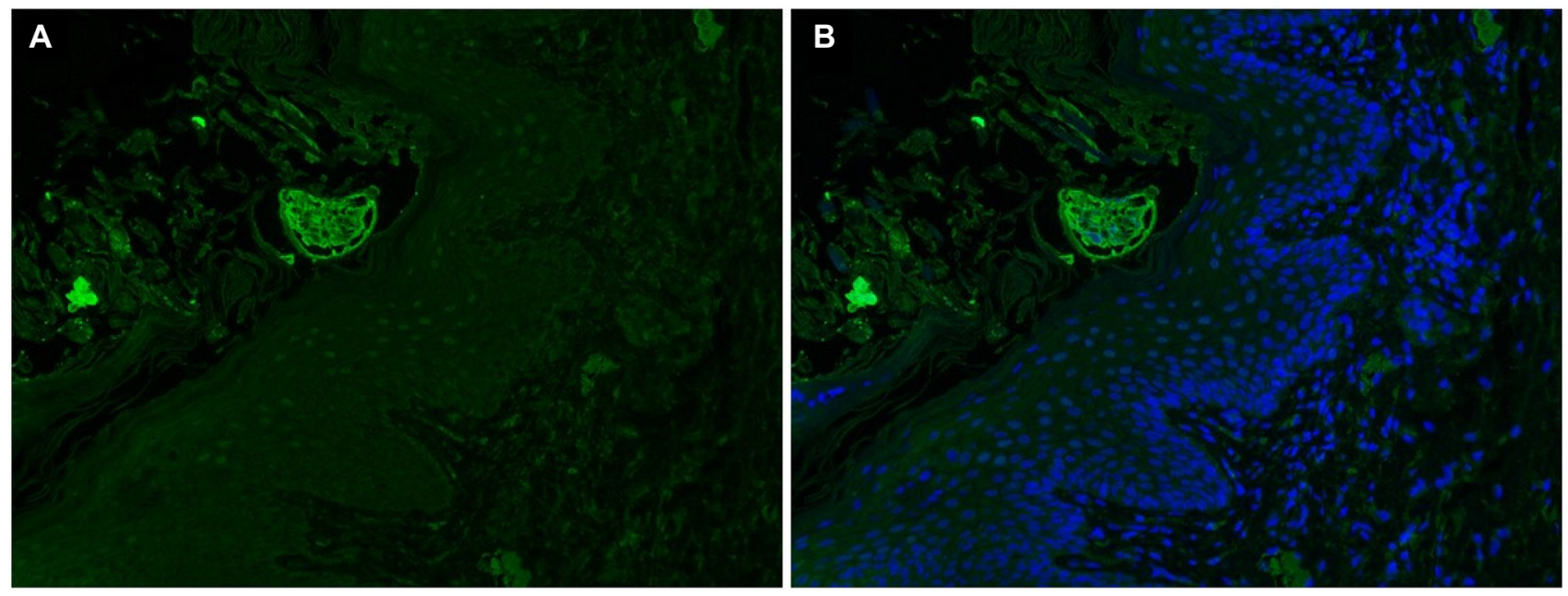

Figure 6: Immunofluorescent localization of SsCLP in S. scabiei-infected rabbit skin. (A and B), SsCLP were distributed in the keratinized skin and embedded mite.
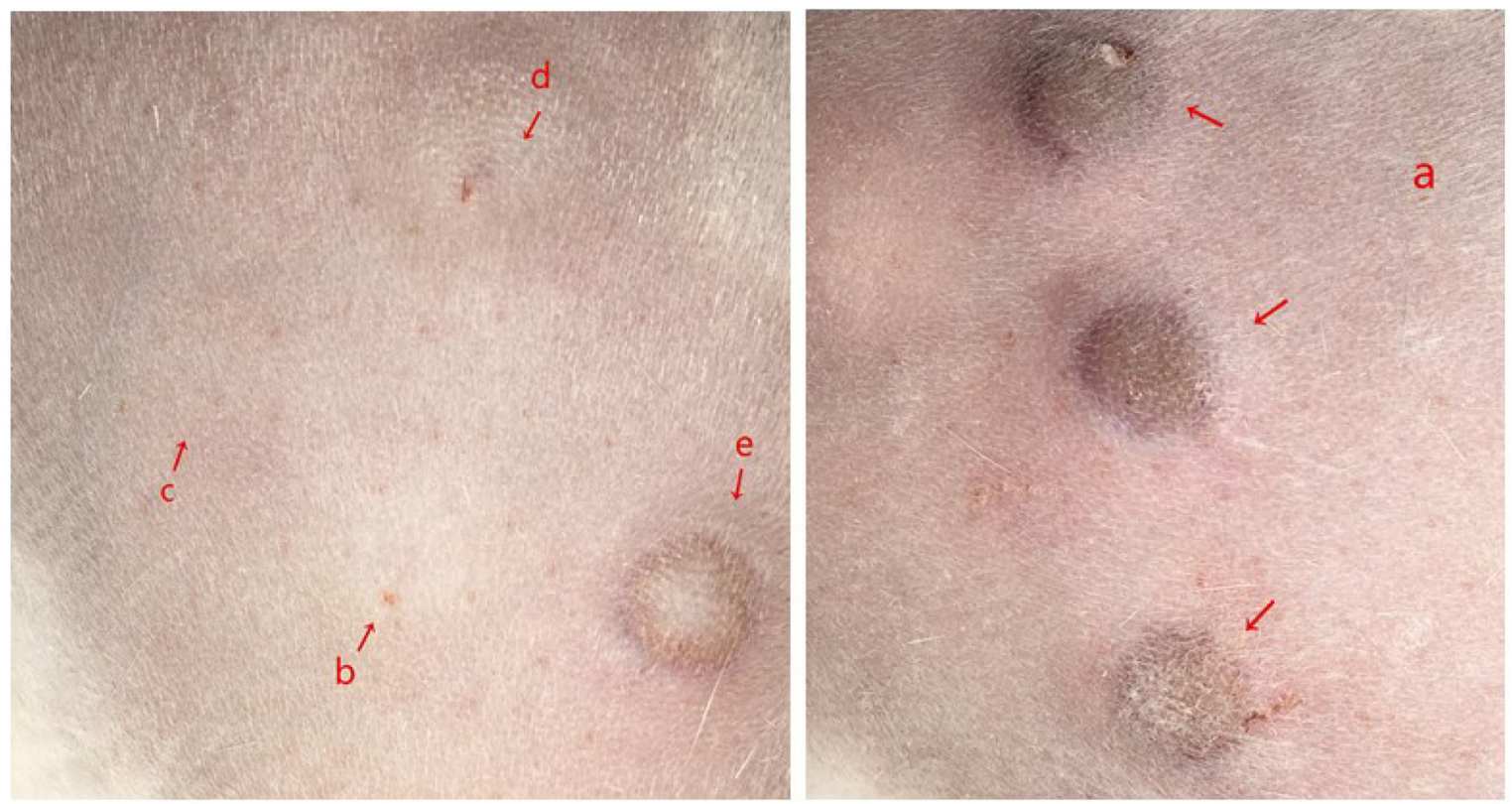

Figure 7: Intradermal skin test on injection of rSsCLP into rabbit. a. 400- $\mu \mathrm{g}$ of purified rSsCLP in $0.1 \mathrm{ml}$ of PBS; b. 400- $\mu \mathrm{g}$ of purified empty expression vector (pET-32a (+) ) in $0.1 \mathrm{ml}$ of PBS; c. $0.1 \mathrm{ml} \mathrm{PBS;} \mathrm{d.} \mathrm{physiological} \mathrm{saline,} 0.9 \%, 0.1 \mathrm{~mL}$; e. histamine, $4 \mathrm{mg} /$ $\mathrm{mL}, 0.1 \mathrm{~mL}$. 
$1: 100$ in $0.1 \%$ Evans blue at $37^{\circ} \mathrm{C}$ for $1 \mathrm{~h}$ in darkness. After washing three times with PBS, the samples were mounted with an anti-fade mounting medium and visualized using a fluorescence microscope. Negative controls were performed with preimmune rabbit serum.

\section{Intradermal skin test}

Because of the lack of an effective secondary antirabbit $\operatorname{IgE}$ antibody, $\operatorname{IgE}$ ELISA and $\operatorname{IgE}$ dot blot are unavailable. Therefore, the allergenic activity of rSsCLP was preliminarily investigated by intradermal skin tests. Three New Zealand White rabbits were injected subcutaneously with $400 \mu \mathrm{g}$ purified rSsCLP in $0.1 \mathrm{ml}$ PBS. The negative controls were: (i) $0.1 \mathrm{~mL}$ PBS; (ii) physiological saline, $0.9 \%, 0.1 \mathrm{~mL}$; and (iii) $400 \mu \mathrm{g}$ of purified empty expression vector $($ pET-32a $(+))$ in 0.1 $\mathrm{mL}$ PBS. The positive control was histamine, $4 \mathrm{mg} / \mathrm{mL}$, $0.1 \mathrm{~mL}$. Skin reactions were observed in the following $30 \mathrm{~min}$ and defined as positive with the presence of a wheal and erythema.

\section{Author contributions}

Ran He and Guangyou Yang conceived and designed the study. Ran He performed the experiments, analyzed the data and wrote the manuscript. Nengxing Shen and Haojie Zhang helped with sample collection and performed experiments. Jing Xu and Yuqin Liang helped with sample collection. Yongjun Ren, Yue Xie, Xuerong Peng, Weimin Lai and Xiaobin Gu helped contribute to study design. All authors read and approved the final manuscript.

\section{ACKNOWLEDGMENTS}

We would like to thank the native English speaking scientists of Elixigen Company (Huntington Beach, California) for editing our manuscript and we are grateful to Xibin Zhao, Xiaoxia Liao for their assistance.

\section{CONFLICTS OF INTEREST}

The authors declare that they have no conflict of interest.

\section{FUNDING}

This work was supported by the Research Fund for the Chengdu Research of Giant Panda Breeding (grant number CPF2014-17). The funder had no role in study design, sample collection, data analysis, preparation or publication of the manuscript.

\section{REFERENCES}

1. Holt DC, Burgess ST, Reynolds SL, Mahmood W, Fischer $\mathrm{K}$. Intestinal proteases of free-living and parasitic astigmatid mites. Cell Tissue Res. 2013; 351:339-52.

2. Rider SD Jr, Morgan MS, Arlian LG. Draft genome of the scabies mite. Parasit Vectors. 2015; 8:1-14.

3. Liu X, Walton S, Mounsey K. Vaccine against scabies: necessity and possibility. Parasitology. 2014; 141:725-32.

4. Fischer K, Walton S. Parasitic mites of medical and veterinary importance-is there a common research agenda? Int J Parasitol. 2014; 44:955-67.

5. Hicks MI, Elston DM. Scabies. Dermatolo Ther. 2009; 22:279-92.

6. Reynolds SL, Pike RN, Mika A, Blom AM, Hofmann A, Wijeyewickrema LC, Kemp D, Fischer K. Scabies mite inactive serine proteases are potent inhibitors of the human complement lectin pathway. PLoS Negl Trop Dis. 2014; 8:e2872.

7. Chung SD, Wang KH, Huang CC, Lin HC. Scabies increased the risk of chronic kidney disease: a 5-year follow-up study. J Eur Acad Dermatolo Venereol. 2014; 28:286-92.

8. Levi A, Mumcuoglu KY, Ingber A, Enk CD. Assessment of Sarcoptes scabiei viability in vivo by reflectance confocal microscopy. Lasers Med Sci. 2011; 26:291-2.

9. Walton SF, Currie BJ. Problems in diagnosing scabies, a global disease in human and animal populations. Clin Microbiol Rev. 2007; 20:268

10. Gao L, Xu GJ, Su H, Gao XG, Li YF, Bao XB, Liu WD, $\mathrm{He}$ CB. Identification and expression analysis of cDNA encoding chitinase-like protein (CLP) gene in Japanese scallop Mizuhopecten yessoensis. Genet Mol Res. 2014; 13:10727-40.

11. Kawamura K, Shibata T, Saget O, Peel D, Bryant PJ. A new family of growth factors produced by the fat body and active on Drosophila imaginal disc cells. Development. 1999; 126:211-9.

12. Badariotti F, Lelong C, Dubos MP, Favrel P. Identification of three singular glycosyl hydrolase family 18 members from the oyster Crassostrea gigas: Structural characterization, phylogenetic analysis and gene expression. Comp Biochem Physiol B Biochem Mol Biol. 2011; 158:56-63.

13. Johansen JS. Studies on serum YKL-40 as a biomarker in diseases with inflammation, tissue remodelling, fibroses and cancer. Dan Med Bull. 2006; 53:172-209.

14. Mizoguchi E. Chitinase 3-like-1 exacerbates intestinal inflammation by enhancing bacterial adhesion and invasion in colonic epithelial cells. Gastroenterology. 2006; 130:398-411.

15. Kucerova L, Broz V, Arefin B, Maaroufi HO, Hurychova J, Strnad H, Zurovec M, Theopold U. The Drosophila chitinase-like protein IDGF3 is involved in protection against nematodes and in wound healing. J Innate Immun. $2015 ; 8: 72-4$. 
16. Bordon Y. Parasite immunity: chitinase-like proteins smoke out worms. Nat Rev Immunol. 2014; 14:775.

17. Lee CG, Elias JA. Role of breast regression protein-39/ YKL-40 in asthma and allergic responses. Allergy Asthma Immunol Res. 2010; 2:20-7.

18. Reese TA, Liang HE, Tager AM, Luster AD, Rooijen NV, Voehringer D, Locksley RM. Chitin induces accumulation in tissue of innate immune cells associated with allergy. Nature. 2007; 447:92-6.

19. Lee CG. Chitin, chitinases and chitinase-like proteins in allergic inflammation and tissue remodeling. Yonsei Med J. 2009; 50:22-30.

20. Arlian LG, Feldmeier H, Morgan MS. The potential for a blood test for scabies. PLoS Negl Trop Dis. 2015; 9:e0004188.

21. He R, Gu X, Lai W, Peng X, Yang G. TranscriptomemicroRNA analysis of Sarcoptes scabiei and host immune response. Plos One. 2017; 12:e0177733.

22. Younes I, Rinaudo M. Chitin and chitosan preparation from marine sources. structure, properties and applications. Marine Drugs. 2015; 13:1133.

23. Gaines PJ, Walmsley SJ, Wisnewski N. Cloning and characterization of five cDNAs encoding peritrophin-A domains from the cat flea, Ctenocephalides felis. Insect Biochem Mol Biol. 2003; 33:1061-73.

24. Suetake T, Tsuda S, Kawabata S, Miura K, Iwanaga S, Hikichi K, Nitta K, Kawano K. Chitin-binding proteins in invertebrates and plants comprise a common chitin-binding structural motif. J Biol Chem. 2000; 275:17929-32.

25. Sutherland TE, Maizels RM, Allen JE. Chitinases and chitinase-like proteins: potential therapeutic targets for the treatment of T-helper type 2 allergies. Clin Exp Allergy. 2009; 39:943-55.

26. Zhu Z, Zheng T, Homer RJ, Kim YK, Chen NY, Cohn L, Hamid Q, Elias JA. Acidic mammalian chitinase in asthmatic Th2 inflammation and IL-13 pathway activation. Science. 2004; 304:1678-82.

27. Kawada M, Hachiya Y, Arihiro A, Mizoguchi E. Role of mammalian chitinases in inflammatory conditions. Keio J Med. 2007; 56: 21.

28. Sutherland TE, Logan N, Rückerl D, Humbles AA, Allan SM, Papayannopoulos V, Stockinger B, Maizels RM, Allen JE. Chitinase-like proteins promote IL-17-mediated neutrophilia in a tradeoff between nematode killing and host damage. Nature Immunol. 2014; 15:1116-25.

29. Lee CG, Silva CA, Cruz CS, Ahangari F, Ma B, Kang MJ, $\mathrm{He} \mathrm{CH}$, Takyar S, Elias JA. Role of chitin and chitinase/ chitinase-like proteins in inflammation, tissue remodeling, and injury. Annu Rev Physiol. 2011; 73:479.

30. He CH, Lee CG, Dela Cruz CS, Lee CM, Zhou Y, Ahangari F, Ma B, Herzog EL, Rosenberg SA, Li Y, Nour AM, Parikh CR, Schmidt I, et al. Chitinase 3-like 1 regulates cellular and tissue responses via IL-13 receptor $\alpha 2$. Cell Rep. 2013; $4: 830$.
31. Ober C, Chupp GL. The chitinase and chitinase-like proteins: a review of genetic and functional studies in asthma and immune-mediated diseases. Curr Opin Allergy Clin Immunol. 2009; 9:401.

32. Dénarié J, Cullimore J. Lipo-oligosaccharide nodulation factors: a minireview new class of signaling molecules mediating recognition and morphogenesis. Cell. 1993; 74:951.

33. Loh JT, Stacey G. Feedback regulation of the Bradyrhizobium japonicum nodulation genes. Mol Microbiol. 2001; 41:1357-64.

34. Arlian LG, Morgan MS. A review of Sarcoptes scabiei: past, present and future. Parasit Vectors. 2017; 10:297.

35. Shimose L, Munoz-Price LS. Diagnosis, Prevention, and Treatment of Scabies. Curr Infect Dis Rep. 2013; 15:426-31.

36. Micali G, Lacarrubba F, Verzì AE, Chosidow O, Schwartz RA. Scabies: advances in noninvasive diagnosis. PLoS Negl Trop Dis. 2016; 10:e0004691.

37. Levitt JO. Digital photography in the diagnosis of scabies. J Am Acad Dermatol. 2008; 59:530.

38. Walter B, Heukelbach J, Fengler G, Worth C, Hengge U, Feldmeier H. Comparison of dermoscopy, skin scraping, and the adhesive tape test for the diagnosis of scabies in a resource-poor setting. Arch Dermatol. 2011; 147:468-73.

39. Alasaad S, Permunian R, Gakuya F, Mutinda M, Soriguer RC, Rossi L. Sarcoptic-mange detector dogs used to identify infected animals during outbreaks in wildlife. BMC Vet Res. 2012; 8:1-7.

40. Lacarrubba F, Verzì AE, Micali G. Detailed analysis of in vivo reflectance confocal microscopy for Sarcoptes scabiei hominis. Am J Med Sci. 2014; 350:414.

41. Naz S, Rizvi DA, Javaid A, Ismail M, Chaudhry FR. Validation of PCR assay for identification of Sarcoptes scabiei var hominis. Iran J Parasitol. 2013; 8:437.

42. Turan E, Erdemir AT, Gurel MS, Basaran YK. The detection of Sarcoptes scabiei in human skin by in vivo confocal microscopy. European J Dermatol. 2012; 21:1004-1005.

43. Angelone-Alasaad S, Min AM, Pasquetti M, Alagaili AN, D'Amelio S, Berrilli F, Obanda V, Gebely MA, Soriguer RC, Rossi L. Universal conventional and real-time PCR diagnosis tools for Sarcoptes scabiei. Parasit Vectors. 2015; 8:587.

44. Zheng Y, He R, He M, Gu X, Wang T, Lai W, Peng X, Yang G. Characterization of Sarcoptes scabiei cofilin gene and assessment of recombinant cofilin protein as an antigen in indirect-ELISA for diagnosis. BMC Infect Dis. 2016; 16:21.

45. Jayaraj R, Hales B, Viberg L, Pizzuto S, Holt D, Rolland JM, O'Hehir RE, Currie BJ, Walton SF. A diagnostic test for scabies: IgE specificity for a recombinant allergen of Sarcoptes scabiei. Diagn Microbiol Infect Dis. 2011; 71:403-7.

46. Nunn FG, Burgess ST, Innocent G, Nisbet AJ, Bates P, Huntley JF. Development of a serodiagnostic test for sheep scab using recombinant protein Pso o 2. Mol Cell Probes. 2011; 25:212-8. 
47. Zhang R, Zheng W, Wu X, Jise Q, Ren Y, Xiang N, Gu $X$, Wang S, Peng X, Lai S, Yang G. Characterisation and analysis of thioredoxin peroxidase as a potential antigen for the serodiagnosis of sarcoptic mange in rabbits by dotELISA. BMC Infect Dis. 2013; 13:336.

48. Hewitson JP, Harcus YM, Curwen RS, Dowle AA, Atmadja AK, Ashton PD, Wilson A, Maizels RM. The secretome of the filarial parasite, Brugia malayi: proteomic profile of adult excretory-secretory products. Mol Biochem Parasitol. 2008; 160:8-21.

49. Geary J, Satti M, Moreno Y, Madrill N, Whitten D, Headley SA, Agnew D, Geary T, Mackenzie C. First analysis of the secretome of the canine heartworm, Dirofilaria immitis. Parasit Vectors. 2012; 5:140.

50. Hewitson JP, Grainger JR, Maizels RM. Helminth immunoregulation: the role of parasite secreted proteins in modulating host immunity. Mol Bioch Parasitol. 2009; 167:1-11.

51. Bennuru S, Semnani R, Meng Z, Ribeiro JM, Veenstra TD, Nutman TB. Brugia malayi excreted/secreted proteins at the host/parasite interface: stage- and gender-specific proteomic profiling. Plos Negl Trop Dis. 2009; 3:e410.

52. Levy DA. Parasites and allergy: from IgE to Th1/Th2 and beyond. Clin Rev Allergy Immunol. 2004; 26:1-4.

53. Hu L, Zhao Y, Yang Y, Niu D, Wang R, Cheng J, Fan Y. De novo RNA-Seq and functional annotation of Sarcoptes scabiei canis. Parasitol Res. 2016; 115:2661-70.
54. Resch Y, Blatt K, Malkus U, Fercher C, Swoboda I, FockeTejkl M, Chen KW, Seiberler S, Mittermann I, Lupinek C, Rodriguez-Dominguez A, Zieglmayer P, Zieglmayer R, et al. Molecular, structural and immunological characterization of Der p 18, a chitinase-like house dust mite allergen. Plos One. 2016; 11:e0160641.

55. Arlian LG, Morgan MS, Rider SD. Sarcoptes scabiei: genomics to proteomics to biology. Parasit Vectors. 2016; 9:380.

56. Aalberse RC. Structural biology of allergens. J Allergy Clin Immun. 2000; 106:228-38.

57. Arlian LG. Arthropod allergens and human health. Annu Rev Entomol. 2002; 47:395-433.

58. Stewart GA, Robinson C. The immunobiology of allergenic peptidases. Clin Exp Allergy. 2003; 33:3-6.

59. Gough L, Schulz O, Sewell HF, Shakib F. The cysteine protease activity of the major dust mite allergen Der $\mathrm{p} 1$ selectively enhances the immunoglobulin E antibody response. J Exp Med. 1999; 190:1897-902.

60. Trompette A, Divanovic S, Visintin A, Blanchard C, Hegde RS, Madan R, Thorne PS, Wills-Karp M, Gioannini TL, Weiss JP, Karp CL. Allergenicity resulting from functional mimicry of a Toll-like receptor complex protein. Nature. 2008; 457:585-8.

61. Gao P. Sensitization to cockroach allergen: immune regulation and genetic determinants. Clin Dev Immunol. 2012; 2012:631847. 